\title{
Investigation of rock bolting for tunnels based on an efficient CATIA-ABAQUS model
}

\author{
Hui Lee ${ }^{1,2}$, Wei-zhong Chen ${ }^{1,3,{ }^{*}}$, Xian-jun Tan ${ }^{1}$, Qiao-chu Yang ${ }^{4}$, and Xiao-gang Wang ${ }^{1,2}$ \\ ${ }^{1}$ State Key Laboratory of Geomechanics and Geotechnical Engineering, Institute of Rock and Soil \\ Mechanics, Chinese Academy of Sciences, Wuhan 430071, China \\ ${ }^{2}$ University of Chinese Academy of Sciences, Beijing 100049, China \\ ${ }^{3}$ Geotechnical and Structural Engineering Research Center, Shandong University, Jinan, Shandong \\ 250061, China \\ ${ }^{4}$ BIM Research Center, Sichuan Highway Planning, Survey, Design and Research Institute Ltd, \\ Chengdu, Sichuan 610000, China
}

\begin{abstract}
As a widely used reinforcement method in tunnel engineering, the accuracy of models in numerical analysis has a vital influence on the reliability of the analysis results. To solve the problem of hard modeling for complicated models, this paper proposes to build models of different characteristics automatically by the means of Enterprise Knowledge Language (EKL) of CATIA, combining knowledge engineering template with parameterization. Furthermore, the stability of surrounding rocks and the distribution features of plastic areas were studied in different cases by CATIA-ABAQUS model. Besides, the effects and contributions of several parameters, including the rock-bolt diameter and interval between rockbolts have been studied. It was found that: (1) Rock-bolt has a notable effect on the stability of the surrounding rocks. Increasing the diameter of rock-bolts contributes to significantly reduce the plastic area and the vertical displacement. With the increase of the quantity and the diameter of anchors, the degree of influence gradually weakens, showing the logarithmic relationship; (2) When the quantity and diameter of rock-bolts are constant, in the case in which the intervals between rock-bolts are various, the plastic area of surrounding rocks and the axial stress of rockbolts are larger than that of the same distance, while the vertical displacement are uniform. (3) The excavation process has a great influence on the axial stress of rock-bolts and the redistribution of stresses in the surrounding rock.
\end{abstract}

Keyword: BIM, Anchoring system, Rock-bolts

\section{Introduction}

The equilibrium state of stress in the surrounding rock will be destroyed owing to excavation. For the surrounding rock of the affect region, a large amount of energy is going to be released by coordinate deformation as well as stress redistribution. If the redistribution stress exceeds the surrounding rock's strength, a lot of new cracks will occur

\footnotetext{
${ }^{*}$ Corresponding author : wzchen@whrsm.ac.cn.
} 
and at the same time, the existed cracks will extend. Finally, all of them affect each other leading to instability and destruction.

Anchoring system can transfer and enhance the strength and self-stability of the rock body by being embedded into it. Scholars did a plenty of works on the anchoring mechanism and optimal design of the anchors and concluded the anchor mechanism of suspension theory, supporting theory, composite theory, enhancement theory and pin theory $[1,2]$. However, the rock bolting design is still empirical or semi-empirical in practical engineering, due to the lack of understanding of bolt reinforcement mechanism [3,4], and the effects and contributions of several parameters are not very clear[5]. Ideally, large-scale physical experiments should be carried out to study the effects and contributions of these parameters. Moreover, (1) it seems to be difficult to get a consistent result, owing to the limitation of the laboratory experimental conditions. For example, the size of the test body can't be cast large enough to satisfy the requirement of testing or to simulate the practical underground geological conditions[6,7]; (2) it is not very convenient for the test bodies to accommodate so many rock-bolts; (3) for larger diameter rock-bolt tests, there was always a lack of sufficient confinement to prevent the split of the test bodies under loading[8]. While, numerical simulations have the advantages of that (1) it is conceivable to satisfy the actual geological conditions as accurate as we need; (2) it can provide further insights and several significant improvements to these models including consistent testing environment which avoids issues of unbalanced forces and insufficient confinement; (3) it is reliable to examine every influence factors whilst obtaining reasonable results[8]; (4) it has the characteristics of repeatability, adjustability, convenience, accuracy, low cost and strong operability[9]. So numerical simulation is a good way to study the optimization of anchoring parameters. On the other hand, whether to generate numerical model accurately is an important factor affecting the accuracy of analysis results, and it seems to be difficult to simulate anchors of different design parameters quickly, accurately and parametrically. CATIA provides a way to build models by parameterizations automatically to reach the purpose of accurate and quick modelling.

In this paper, the simulation of excavation and rock-bolt reinforcement in a large scale of rock body has been performed by parameterized modeling in CATIA and analyzing in ABAQUS. It aims to further understanding of the influence of relevant parameters, the distribution of stress and stability of surrounding rocks for the optimization of anchors.

\section{Model building and cases study}

\subsection{Model building}

The parameters of the practical project including intervals and diameters of each anchor are easy to adjust for various research purpose in order to optimize the anchoring system by the means of parameterized design module of CATIA[10,11], so as to build the design model (Fig.1). The model is imported into ABAQUS for the CATIA-ABAQUS simulation model to analyze the influence of excavation on the stability and stress redistribution of surrounding rock, and investigate the factors and contributions of the influence factors on the stability of surrounding rock to realize the fusion of numerical simulation and BIM. The simulation process is shown in Fig.2. For the sake of simplification, the geological-terrain model was simplified as a cube in this research. 


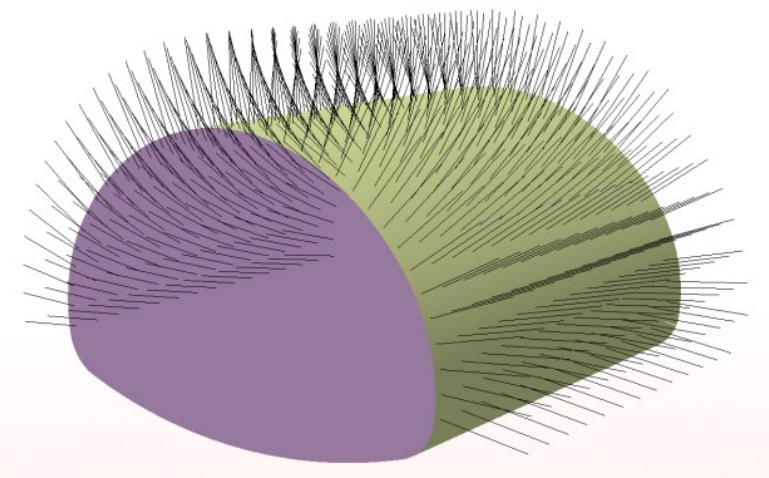

Fig. 1. The layout of the model

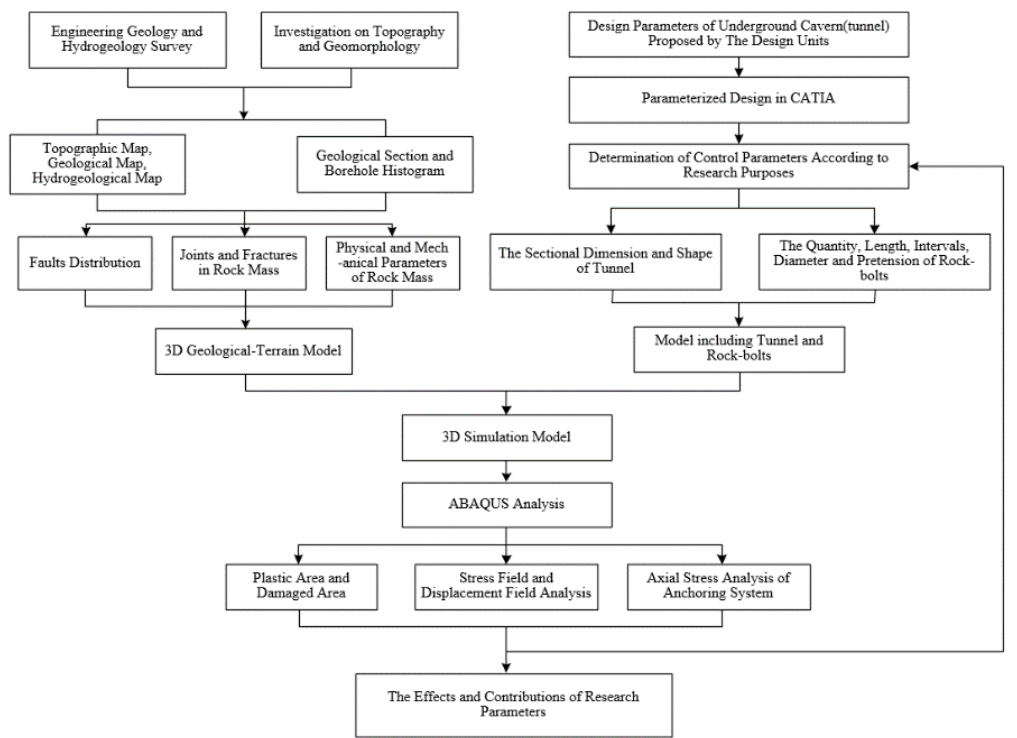

Fig. 2. Simulation process

The study model consisted of two types of materials: rock body and steel (rock-bolt). In the numerical simulation, the rock body was modelled as the Mohr-Coulomb criterion, elasto-plastically and the rock-bolt was modelled as truss of linear elastic model. The interface between rock-bolts and rock mass was simulated by embedded elements which means the nodes of rock-bolt elements are inserted in the rock mass element by interpolation method. Reasonable material property is crucial to obtain correct simulation results. Table 1 and 2 show the material properties that were used in the numerical simulation.

Table 1. Material properties of the rock body

\begin{tabular}{|c|c|c|c|c|}
\hline $\begin{array}{c}\text { Density/(kg · } \\
\left.\mathbf{m}^{-\mathbf{3}}\right)\end{array}$ & $\begin{array}{c}\text { Elastic } \\
\text { modulus/MPa }\end{array}$ & $\begin{array}{c}\text { Poisson's } \\
\text { ratio }\end{array}$ & Cohesion/MPa & $\begin{array}{c}\text { Friction } \\
\left.\text { angle/( }{ }^{\circ}\right)\end{array}$ \\
\hline 2500 & 1200 & 0.35 & 0.2 & 25 \\
\hline
\end{tabular}

Table 2. Material properties of rock-bolt

\begin{tabular}{|l|l|l|l|l|}
\hline Density /(kg • & Elastic modulus & Poisson's & Coefficient of expa & Pretension/M \\
\hline
\end{tabular}




\begin{tabular}{|c|c|c|c|c|}
\hline $\mathbf{m}^{-\mathbf{3}} \mathbf{)}$ & $/ \mathbf{M P a}$ & ratio & nsion & Pa \\
\hline 6000 & 200000 & 0.25 & $1.3 \times 10^{-5}$ & 260 \\
\hline
\end{tabular}

\subsection{Cases study}

To avoid steel wasting and to shorten the period of construction, it's important to optimize the design of rock-bolts, including the length and the diameter of rock-bolts, rock-bolt inclination, interval between rock-bolts, and so on. So numerical simulation was carried out to investigate the influences and contributions of various parameters on the stability of rock body, stress distribution of rock body and rock-bolts, and the convergence of surrounding rock.

Rock-bolts with different setting formations and diameters, 18, 22, 25, 28, and $32 \mathrm{~mm}$, were embedded in rock body which was with the size of $260 \mathrm{~m} \times 20 \mathrm{~m} \times 154 \mathrm{~m}$. The length of rock-bolts was $4 \mathrm{~m}$, whole of which was embedded into the rock body. The boundary conditions applied in the model were that the bottom side of the model was displacement limited at 3 directions, and the side face was limited to normal displacement constraint. Every two layers of rock-bolts were set as rectangular (Fig.1). In this paper, we considered the length and the inclination of rock-bolt as invariants, and the variables investigated are listed in Table 3. Besides, this paper considered the effect of excavation process[12]by dividing the tunnel into three sections for full section excavation.

Table 3. The variables and invariants investigated in this paper

\begin{tabular}{|l|l|l|}
\hline \multicolumn{2}{|l|}{ Variables } & Invariants \\
\hline \multirow{3}{*}{ Intervals between rock-bolts } & $1.6 \mathrm{~m} \times 1.6 \mathrm{~m} 1.2 \mathrm{~m} \times 1.2 \mathrm{~m}$ & \\
& $0.8 \mathrm{~m} \times 0.8 \mathrm{~m} 0.6 \mathrm{~m} \times 0.6 \mathrm{~m}$ & \\
\cline { 1 - 2 } Rock-bolt diameter & $0.4 \mathrm{~m} \times 0.4 \mathrm{~m}$ & $90^{\circ}, 4000 \mathrm{~mm}$ length, 260MPa \\
& $18 \mathrm{~mm}, 22 \mathrm{~mm}, 25 \mathrm{~mm}$, & \\
& $28 \mathrm{~mm}, 32 \mathrm{~mm}$ & \\
\hline
\end{tabular}

\section{Numerical analysis and results}

As the quantity of output results were so large, only the main results were presented here. We considered the convergence to be one of the crucial criterion for the stability of the tunnel. So this paper discussed how the quantity (interval between rock-bolts longitudinal and tangent) and the diameter of rock-bolts affect the vertical displacement of the tunnel. Additionally, the characteristics of plastic zone, stress field and the axial stress of rock-bolts were studied.

\subsection{Plastic zone analysis}

Only part of typical characteristics of the plastic zones were discussed in which no rockbolt existed or the distance between rock-bolts longitudinal and tangent are both $1.6 \mathrm{~m}$, $0.8 \mathrm{~m}, 0.4 \mathrm{~m}$, respectively. Fig. 3 shows that the plastic zone without rock-bolt is mainly concentrated on the arch hance and arch spandrel, like a couple of wing. While the features changed when rock-bolt existed and different characteristics could be seen as the distance between rock-bolts differs. The area of plastic zone reduces as the setting density becoming large and focuses on the bottom of the arch which means rock-bolt is useful for inhibiting the extension of stress and strengthening the surrounding rock to improve its own strength.

In fact, what rock-bolts do to improve the stability of the surrounding rock is called anchorage effect. Excavation of tunnel leading to unload of rock and stress redistribution is the key factor to rock deformation. To avoid exceeding displacement, anchoring system is 
needed. As long as the surrounding rock deforms, the rock-bolts embedded in the rock body will lead to additional radial force and the stress distribution of the rock translates from two-directional stress state to three-directional stress state[13]. The tunnel whose section is circle forms a supporting ring and the tunnel with arch section forms a supporting arch, both of which avoid the deterioration of the property of rock body. Additionally, the physical and mechanical properties of the medium composed of steel and rock are ideally much higher than rock. In this paper, we improved the properties Elastic module, Poisson's ratio, Cohesion by $10 \%[14]$.

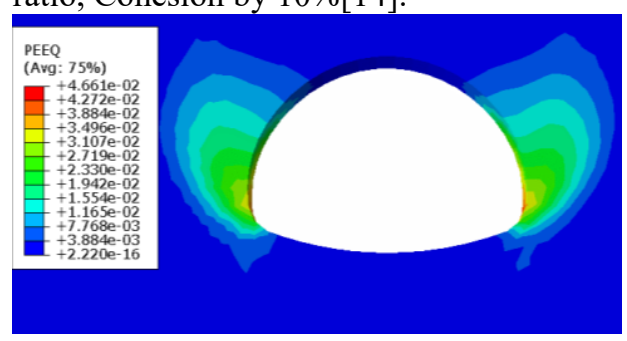

(a) without rock-bolt

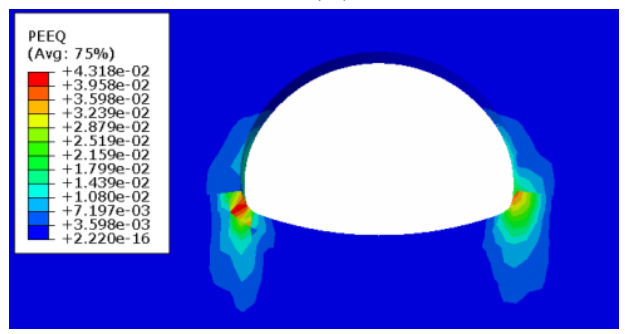

(c) $0.8 \mathrm{~m} \times 0.8 \mathrm{~m}$

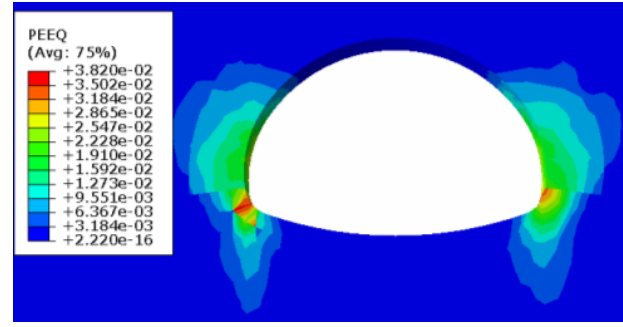

(b) $1.6 \mathrm{~m} \times 1.6 \mathrm{~m}$

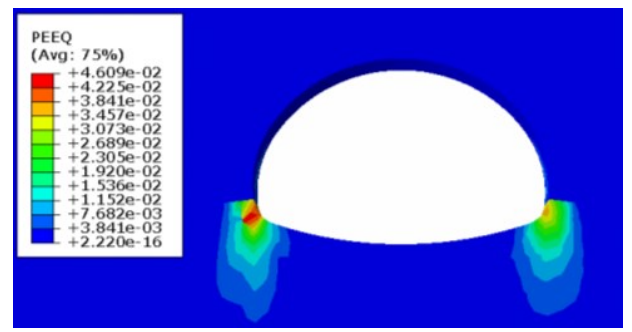

(d) $0.4 \mathrm{~m} \times 0.4 \mathrm{~m}$

Fig. 3. The plastic zone distribution with setting density increasing

\subsection{Stress field analysis}

Take the stress distribution of the tunnel vault (called "line" below) with various rock-bolt's setting formations for example.

Fig.4(a) shows that the regular of the radial stress distribution without rock-bolt is different from that with rock-bolt. If no rock-bolt is embedded, with an increase of the distance from the tunnel wall, the radial stress of "line" increases gradually, then it's going to be stable. When rock-bolts exist, the radial stress of "line" increases to a maximum and then decreases gradually in the anchoring area. Beyond the anchoring area, the radial stress increases to a stable value. Take the case in which the distance between longitudinal and tangent rock-bolt are both $0.6 \mathrm{~m}$ for example, the radial stress of the first observation point on the tunnel wall is $0.6 \mathrm{MPa}$, while it increases with the distance from the tunnel wall, and reaches the maximum at the fourth observation point. Then, it decreases to $0.28 \mathrm{MPa}$ at the fifth observation point. At last, out of the anchoring area, the radial stress raises as the distance from the tunnel wall. What's more, the more the rock-bolts are, the larger the radial stress on the tunnel wall is, and the maximum of the radial stress increases as well. When the distance of longitudinal and tangent rock-bolts are both $1.6 \mathrm{~m}, 1.2 \mathrm{~m}, 0.8 \mathrm{~m}, 0.6 \mathrm{~m}$, and $0.4 \mathrm{~m}$, the radial stress on the tunnel wall is $0.167 \mathrm{MPa}, 0.207 \mathrm{MPa}, 0.398 \mathrm{MPa}$, $0.604 \mathrm{MPa}, 1.006 \mathrm{MPa}$, respectively; the maximum stress of this line is $0.247 \mathrm{MPa}$, $0.314 \mathrm{MPa}, 0.483 \mathrm{MPa}, 0.659 \mathrm{MPa}, 1.062 \mathrm{MPa}$, respectively. The mechanism of this phenomenon is that excavation led to rock low stability and stress redistribution. If the anchoring system is not applied, the strength of the rock decreases to the residual stress, instead, the stress of the surrounding rock redistributes again because of the anchoring force 
which constitutes of the stress of the surrounding rock with initial stress. As a result, the maximum stress and residual stress increase as the strength of the anchoring system improves. On the other hand, due to the enhancement theory of rock-bolt, the physical and mechanical properties of the rock-bolt are improved and they improve a lot as the setting density is enhanced which also leads to the improving of the anchoring effect, suggesting that the radial stress improves with the setting density.

As shown in Fig.4(b), no matter the rock-bolt exists or not, the regular of the tangent stress on the vault of the tunnel exists a concentration value in the anchoring area, and then decreases to a stable value. But the difference is that the maximum of the tangent stress anchored is much bigger than that without rock-bolt. The tangent stress and the maximum tangent value are both increase with the setting density increasing, and they tend to be the same value at last. For example, when the longitudinal and tangent interval are both $1.6 \mathrm{~m}$, $1.2 \mathrm{~m}, 0.8 \mathrm{~m}, 0.6 \mathrm{~m}$, and $0.4 \mathrm{~m}$, the tangent stress of the tunnel wall is $0.698 \mathrm{MPa}, 0.729 \mathrm{MPa}$, $0.815 \mathrm{MPa}, 0.871 \mathrm{MPa}, 0.952 \mathrm{MPa}$, respectively; the maximum value of the tunnel vault is $0.792 \mathrm{MPa}, 0.853 \mathrm{MPa}, 0.972 \mathrm{MPa}, 1.061 \mathrm{MPa}, 1.212 \mathrm{MPa}$, which is much bigger than that without rock-bolt $(0.60 \mathrm{MPa}, 0.61 \mathrm{MPa})$.

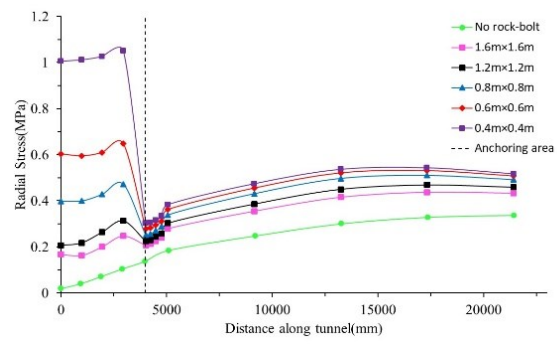

(a)

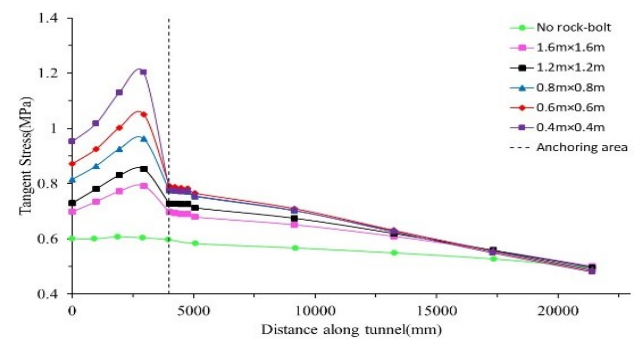

Fig. 4. The distribution of radial and tangent stress at various cases. (a) Radial stress, (b) Tangent stress.

\subsection{Displacement field analysis}

\subsubsection{Influence of quantity}

The effect of different setting density of rock-bolts on the radial convergence of the tunnel vault is shown in Fig.5. It can be seen that the stability of the surrounding rock has been greatly improved. Take the rock-bolts set as $1.6 \mathrm{~m} \times 1.6 \mathrm{~m}$ for example, the vertical displacement of the vault is about $-26 \mathrm{~mm}$, which reduces by $23.5 \%$ compared with $-34 \mathrm{~mm}$ without rock-bolt, and reduces by $27.6 \%, 35.3 \%, 39.7 \%, 44.1 \%$, respectively, for rock-bolts set as $1.2 \mathrm{~m} \times 1.2 \mathrm{~m}, 0.8 \mathrm{~m} \times 0.8 \mathrm{~m}, 0.6 \mathrm{~m} \times 0.6 \mathrm{~m}, 0.4 \mathrm{~m} \times 0.4 \mathrm{~m}$. With the longitudinal and tangent distance becoming small, the vertical displacement of the tunnel vault reduces significantly, the degree of which is in terms of the quantity of rock-bolt (Table 4). As shown in Fig.6, the deformation decreases as the quantity of rock-bolts increases, suggesting that they have obviously positive correlation with each other. When the quantity of rock-bolt is not very large, the deformation increases significantly with it and it does not increases obviously as the quantity increases, suggesting the property of convex function [9]. The characteristic is consistent with the results obtained by DEM[15]. It indexes that the regular of "the more, the better" is not reliable, we'd better choose the proper setting formation according to the vertical displacement.

Table 4. The quantity of anchors of different setting formation

\begin{tabular}{|l|c|c|c|c|c|c|c|}
\hline Formation & $1.6 \mathrm{~m} \times 1.6 \mathrm{~m}$ & $1.2 \mathrm{~m} \times 1.2 \mathrm{~m}$ & $0.8 \mathrm{~m} \times 0.8 \mathrm{~m}$ & $0.6 \mathrm{~m} \times 0.6 \mathrm{~m}$ & $0.4 \mathrm{~m} \times 0.4 \mathrm{~m}$ & $1.0 \mathrm{~m} \times 1.4 \mathrm{~m}$ & $0.6 \mathrm{~m} \times 1.1 \mathrm{~m}$ \\
\hline
\end{tabular}




\begin{tabular}{|c|c|c|c|c|c|c|c|}
\hline Quantity & 286 & 522 & 1276 & 1972 & 4472 & 525 & 522 \\
\hline
\end{tabular}

The effect of the quantity of rock-bolts on the vertical displacement has been studied by the means of statistical method. The expression about the quantity of rock-bolts and the vertical displacement for tunnel vault and spandrel are listed in Eq.(1) and Eq.(2), respectively, and these equations can be translated into ordinary formation (Eq.(3)).

$$
\begin{gathered}
y_{\mathrm{N}}=2.897 \times \ln \left(x_{\mathrm{N}}\right)-42.7 \\
y_{\mathrm{N}}=3.307 \times \ln \left(x_{\mathrm{N}}\right)-43.403 \\
y_{\mathrm{N}}=a_{\mathrm{N}} \times \ln \left(x_{\mathrm{N}}\right)+b_{\mathrm{N}}
\end{gathered}
$$

where $y_{\mathrm{N}}$ is the vertical displacement, $x_{\mathrm{N}}$ is the quantity of rock-bolts. In these equations the $\mathrm{R}^{2}$ is 0.9882 and 0.9827 , respectively, which means that the statistics fit well.

Obviously, there is logarithmic relationship between the quantity of rock-bolts and the vertical displacement. In Eq.(3) $a_{\mathrm{N}}$ and $b_{\mathrm{N}}$ are parameters needed to be confirmed by the means of experiment or numerical simulation which are in terms of the lithology. As long as the expression is quantified, it is possible to get the quantity of rock-bolts according to the conditional parameters -- vertical displacement, then to confirm the setting formation.

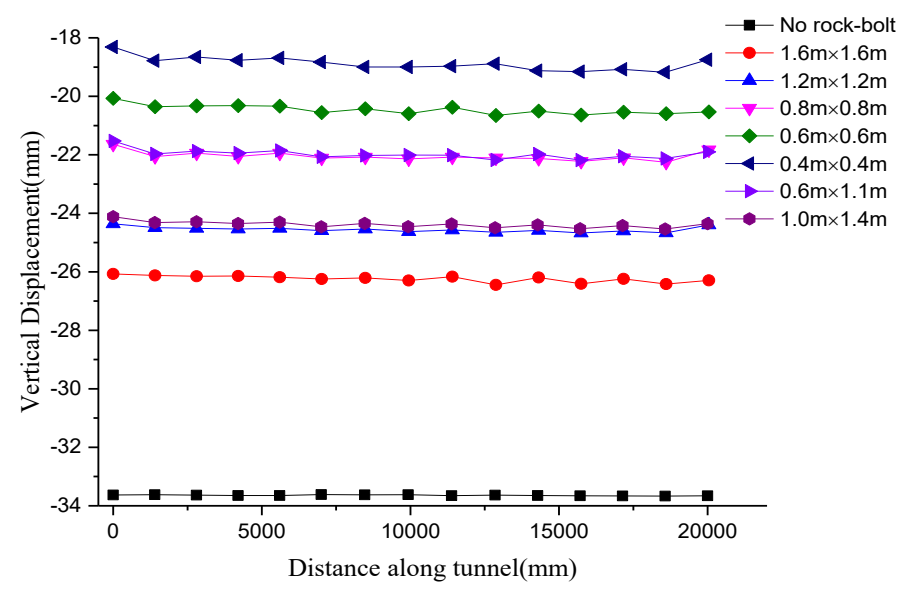

Fig. 5. The vertical displacement of the tunnel vault at different cases

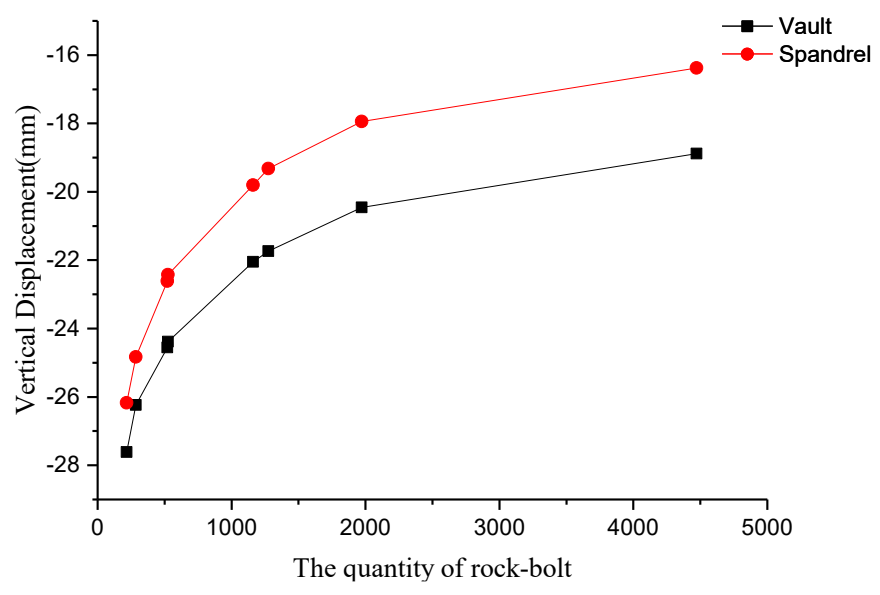

Fig. 6. Influence of the quantity of rock-bolts on the vertical displacement 


\subsubsection{Influence of diameter}

In this numerical model, the longitudinal and tangent distance of rock-bolts are both $0.6 \mathrm{~m}$, and the diameter is set to $18 \mathrm{~mm}, 22 \mathrm{~mm}, 25 \mathrm{~mm}, 28 \mathrm{~mm}$, and $32 \mathrm{~mm}$, while other parameters are kept consistent with those in Table 1,2. The results of the vertical displacement are shown in Table 5, and the features of the vertical displacement versus the diameter of rockbolts are shown in Fig.7, which is similar with the effect caused by the quantity of rockbolts. With the diameter of rock-bolt increasing, the vertical displacement does not reduce significantly. Similarly, we studied it with the method of statistical method, and the result is concluded with Eq.(4) and Eq.(5) for tunnel vault and spandrel, respectively. Like the phenomenon discussed above, the parameters called $a_{\mathrm{D}}$ and $b_{\mathrm{D}}$ are parameters which should be defined by laboratory test, field test or numerical simulation. So for the specifical project, the diameter of the rock-bolts can been chosen using Eq.(6).

$$
\begin{gathered}
y_{\mathrm{D}}=4.8125 \times \ln \left(x_{\mathrm{D}}\right)-36.011 \\
y_{\mathrm{D}}=4.77 \times \ln \left(x_{\mathrm{D}}\right)-35.609 \\
y_{\mathrm{D}}=a_{\mathrm{D}} \times \ln \left(x_{\mathrm{D}}\right)+b_{\mathrm{D}}
\end{gathered}
$$

where $y_{\mathrm{D}}$ is the vertical displacement, $x_{\mathrm{D}}$ is the diameter of rock-bolts. In these equations the $\mathrm{R}^{2}$ is 0.9953 and 0.9945 , which means that the statistics fit well.

When the rock is unloaded, the surrounding rock deforms into blocks and the radial anchoring force is imposed on the rock body leading to rock compression. The cracks are closed, then the cohesion and frictional angle increase, the strength of the surrounding rock is enhanced[16]. If the quantity of the rock-bolts reaches to a critical value, the cracks are all closed and the rock body reaches to a limitation of the extrusion deformation. Beyond the critical, new cracks will appear which weaken the integrity and the stability of the rock.

Table 5. The vertical displacement under various diameters of rock-bolts

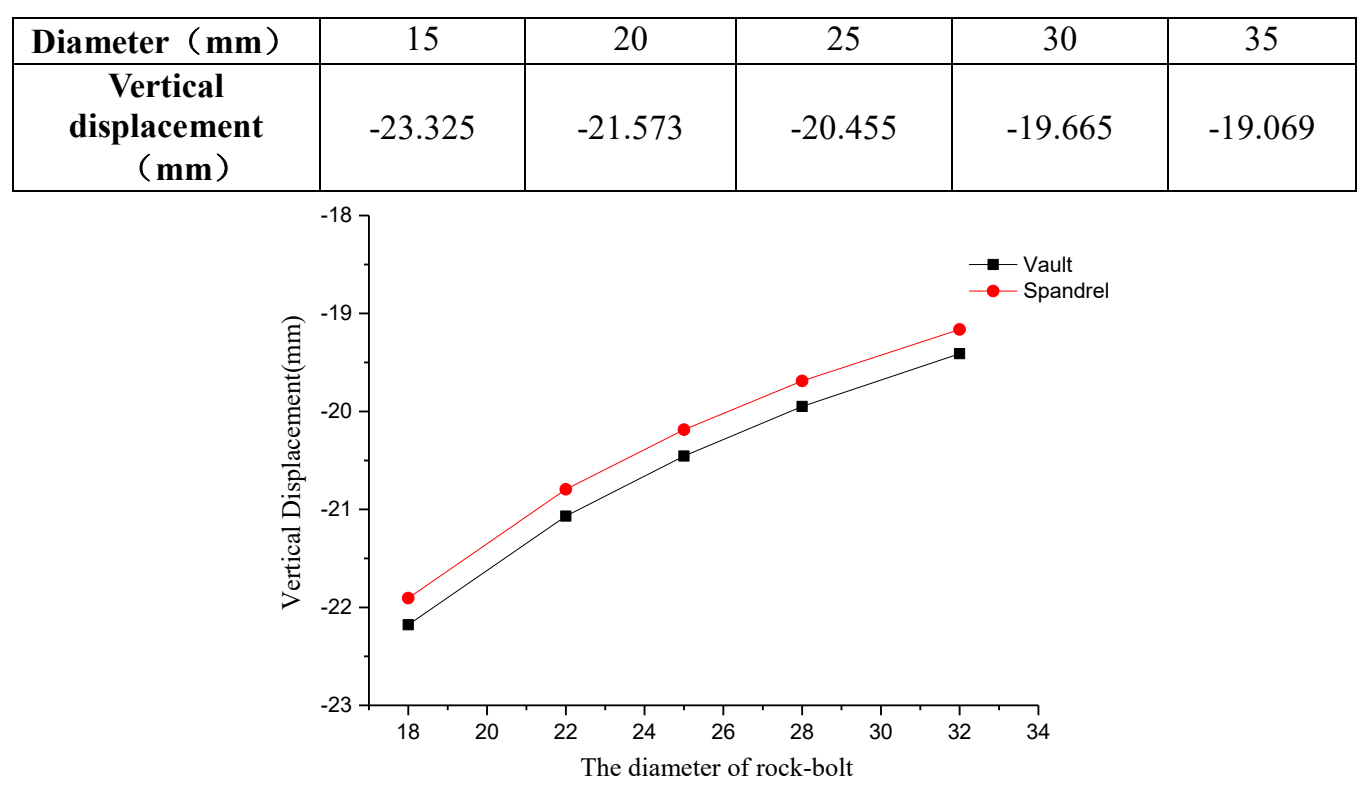

Fig.7. The vertical displacement with different diameters 


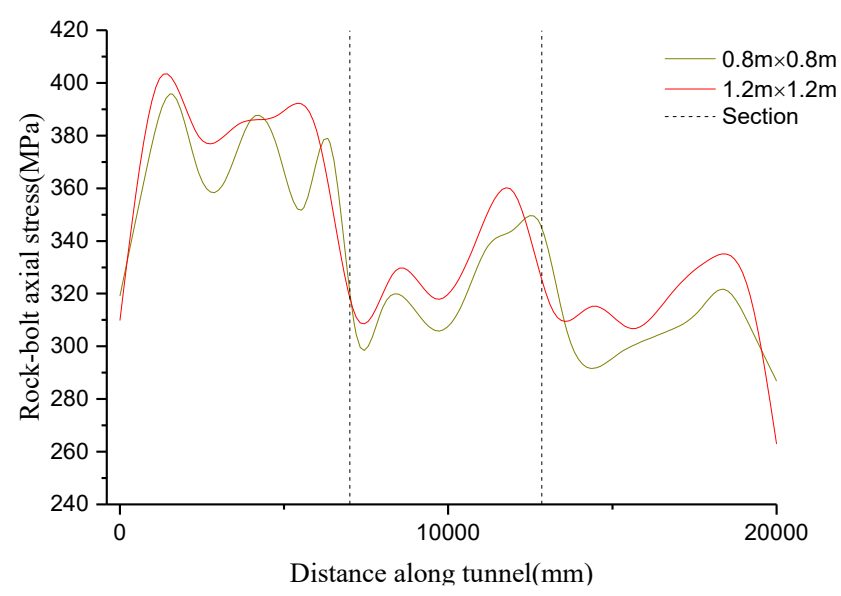

Fig. 8. Influence of excavation process on axial stress

\subsection{Axial stress analysis}

From the results discussed above, the effect on the stability of the surrounding rock of the longitudinal and tangent interval is due to the quantity of rock-bolts, suggesting that it is none of the interval's business, but it will differ a lot for the axial stress of rock-bolt.

When the quantity of rock-bolt is closed to each other, we need to study the axial stress distribution of rock-bolt. Take the cases in which rock-bolts are set as $1.0 \mathrm{~m} \times 1.4 \mathrm{~m}, 1.2 \mathrm{~m} \times$ $1.2 \mathrm{~m}$ for example, there are 525 rock-bolts in the former case, and 522 in the latter one.

The distribution of rock-bolt axial stress versus each excavation section is shown in Fig.8, and it can be seen that the axial force of the rock-bolt is a fluctuating distribution in each excavation section, with multiple extremums and one maximum. In order to do some research on the distribution of rock-bolt axial stress along the length, we studied the average axial stress of the tunnel vault and the hance in two cases. Fig.9(a) shows the characteristics of the axial stress versus the length of rock-bolt in the hance of the tunnel, showing a maximum at $601.92 \mathrm{~mm}$ with value of $830 \mathrm{MPa}$ for the case of $1.0 \mathrm{~m} \times 1.4 \mathrm{~m}$, and a maximum at $401.25 \mathrm{~mm}$ with value of $828.6 \mathrm{MPa}$ for the case of $1.2 \mathrm{~m} \times 1.2 \mathrm{~m}$. It can be seen that the maximums are similar in the two cases, but the maximum stress of the latter is closer to the tunnel wall than the former, and the maximum stress of the rock-bolt in both formations are offset the middle position and close to the inside part of the tunnel.

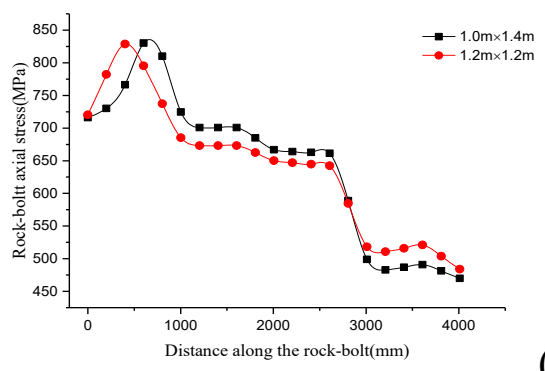

(a)

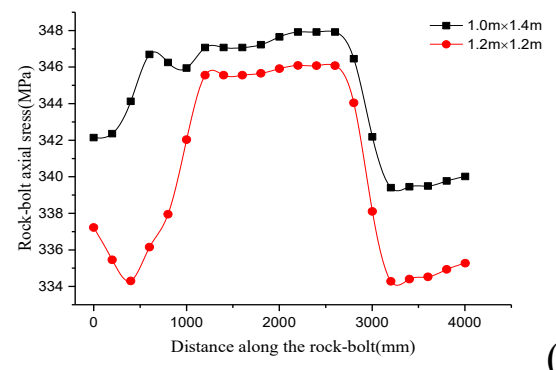

Fig. 9. The axial stress distribution along the length of rock-bolt under different setting arrangements.

(a) The hance of tunnel, (b) The tunnel vault. 
Fig.9(b) shows the distribution of axial stress at the tunnel vault in the two cases, presenting the similar features, but the axial stress of the former is slightly higher than that of the latter.

By analyzing the distribution characteristics of the axial stress of the two cases, it can be seen that when the quantity of rock-bolts is similar, the effect they do on the stability of the surrounding rock is also the same and the vertical displacement can be calculated by Eq.(3) or Eq.(6). While, the plastic area of the former case is much larger than that of the latter and the axial stress of rock-bolts is also higher which means that the risk of instability increases. Therefore, we'd better choose the equivalent longitudinal and tangent intervals between rock-bolts when the quantity of rock-bolts is constant.

\section{Conclusions}

In this study, an accurate model was built by CATIA, and was employed in the mechanical analysis of the bolt-reinforced tunnel which was excavated by full excavation for three sections. Besides, the factors and contributions of the parameters which have influence on the rock body have been studied by the means of numerical simulation. Primary conclusions are summarized as follows.

(1) The increasing quantity of rock-bolts contributed to significantly reduce the plastic zone and the vertical displacement. While, it does not increase obviously any more with the number of rock-bolts increasing, which is the law of logarithm function, so as to the effect of the diameter of rock-bolt.

(2) The process of excavation matters a lot to the rock-bolts axial force, and several extremum values and one maximum exist on the rock-bolt axial force along the length of tunnel.

(3) For the rectangular arrangement formation, the influence of the intervals between rock-bolts on the stability of the surrounding rock is due to the impact of the quantity of anchors, but the longitudinal and tangent rock-bolts with same intervals is stable than that of different one.

\section{References}

1. S.R. Zhang, Y. Gu, Z.L. Zhang. The optimized design of rock-bolts supporting the large-scale underground cavities[J]. Journal of Hydroelectric Engineering, 26(5):4752(2007)

2. L.W Zhang, R. Wang. Research on status quo of anchorage theory of rock and soil[J]. Rock and Soil Mechanics, 23(5):627-631(2002)

3. Y. Cai, T. Esaki, Y.J. Jiang. An analytical model to predict axial load in grouted rock bolt for soft rock tunnelling[J]. Tunnelling and Underground Space Technology, 19(6) : 607-618(2004a)

4. Y. Cai, T. Esaki, Y.J. Jiang. A rock bolt and rock mass interaction model[J]. International Journal of Rock Mechanics \& Mining Sciences, 41(7):1055-1067(2004b)

5. J.C. Gu, J. Shen, A.M. Chen, et al. Model testing study of strain distribution regularity in rock mass caused by prestressed anchorage cable[J]. Rock Mechanics and Rock Engineering, 19(Z1):917-921(2000)

6. A.T. Haile. A mechanistic evaluation and design of tunnel support systems for deep level South African mines. PhD thesis (unpublished), University of Natal, Durban, South Africa(1999a)

7. A.T. Haile. Observation of the dynamic support performance of South African tunnel support systems. In: Proceedings rock support and reinforcement practice in mining, 
Kalgoorlie, Australia, 335-341(1999b)

8. L. Li. Parametric Study of Rockbolt Shear Behaviour by Double Shear Test[J]. Rock Mechanics and Rock Engineering, 49(12):4787-4797(2016)

9. Q.L. Dong, Research on deformation law of weak broken roadway and optimization of bolt support parameters under mining influence[D]. GuiZhou University(2018)

10. X.C. Han. Research on Application of BIM Concept Tunnel Portal Design Program[D]. Chongqing Jiaotong University(2018)

11. X. Qin. Research on Railway Geological Route Selection Method Based on BIM[D]. Shijiazhuang Tiedao University(2018)

12. G.L. Han. Analysis of Mechanism of Bolt-Anchor Cable Combined Support for Weak Rock Cavern by ABAQUS[J]. Metal Mine, 75-79(2008)

13. P.P. Chen, Q.W. Xu, H.H. Zhu, et al. Model experiment study on the failure characteristics of weak surrounding rock mass above tunnel arch and the anchoring effect of bolts[J]. Chinese Journal of Rock Mechanics \& Engineering, 35(S2):35613569(2016)

14. H. Chen, W.Z. Ren, D. Li, et al. Numerical simulation and model test study of mechanism of bolt in deep tunnel[J]. Rock and Soil Mechanics, 32(S1):719-724(2011)

15. H.N. Wang, X. Guo, M.J. Jiang, et al. Investigation of rock bolting for deeply buried tunnels via a new efficient hybrid DEM-Analytical model[J]. Tunnelling and Underground Space Technology, 82:366-379(2018)

16. H. Chen, W.Z. Ren, Z.G. Shu, et al. Model test study and numerical analysis of mechanism of anchor bolt under different supporting conditions[J]. Rock \& Soil Mechanics, 33(S1):277-282(2012) 